\title{
C-reactive protein, a disintegrin and metalloproteinase 17 protein, and ca- thepsin D in chronic periodontitis with type 2 diabetes mellitus
}

\author{
Keung-Ky Moon, Hak-Ki Kim, Yong-Gun Kim, Jo-Young Suh, Jae-Mok Lee*
}

Department of Periodontology, School of Dentistry, Kyungpook National University, Daegu, Korea

\begin{abstract}
The purpose of this study was to compare and quantify the expression of C-reactive protein (CRP), a disintegrin and metalloproteinase 17 (ADAM17) protein, and cathepsin D in the gingival tissues of patients with type 2 diabetes mellitus (DM) with those in healthy adults with chronic periodontitis. Gingival tissue samples were obtained during periodontal surgery or tooth extraction. Depending on the patient's systemic condition and clinical criteria of gingiva, each gingival sample was divided into three groups. Group $1(\mathrm{n}=12)$ included clinically healthy gingiva without bleeding and no evidence of bone resorption or periodontal pockets. Group $2(\mathrm{n}=12)$ included inflamed gingiva from patients with chronic periodontitis. Group $3(n=12)$ included inflamed gingiva from patients with chronic periodontitis associated with type $2 \mathrm{DM}$. Tissue samples were prepared and analyzed using Western blotting. The relative quantifications of CRP, ADAM17 protein, and cathepsin D were performed with a densitometer, and the results were statistically analyzed by one-way analysis of variance followed by Tukey test. The expression levels of CRP, ADAM17 protein, and cathepsin D increased in groups 2 and 3 compared with those in group 1 . The differences among three groups were statistically significant $(p<0.05)$. In conclusion, this study demonstrated that the expression levels of CRP, ADAM17 protein and cathepsin D might act as inflammatory markers in periodontal inflamed tissue. It can be assumed that CRP, ADAM17 protein, and cathepsin D are partly involved in the progression of periodontal inflammation associated with type $2 \mathrm{DM}$.
\end{abstract}

Key Words: ADAM17 protein, Cathepsin D, Chronic periodontitis, C-reactive protein, Diabetes mellitus

@) This is an open-access article distributed under the terms of the Creative Commons Attribution Non-Commercial License (http://creativecommons.org/licenses/by-nc/4.0) which permits unrestricted noncommercial use, distribution, and reproduction in any medium, provided the original work is properly cited.

\section{INTRODUCTION}

Periodontal disease is a chronic inflammatory disorder by the anaerobic bacteria invasion into periodontal tissues including gingival connective tissue, periodontal ligament, and alveolar bone. Destructive periodontal disease is predominantly associated with an anaerobic gram-negative microflora, and species such as Porphyromonas gingivalis, Aggregatibacter actinomycetemcomitans, Tannerella for- sythia, and Treonema denticola have been associated with the disease [1-3].

This chronic disease manifests clinically as at least two distinct entities. Microbiological, immunological and animal model studies have shown that some forms of periodontal disease (gingivitis) in adults can remain stable throughout many years and not endanger the life of the dentition, whereas other forms (periodontitis), despite extensive treatment, continue to break down leading ultimately to

Received August 19, 2019; Revised September 5, 2019; Accepted September 5, 2019

Corresponding author: Jae-Mok Lee, Department of Periodontology, School of Dentistry, Kyungpook National University, 2177 Dalgubeoldaero, Jung-gu, Daegu 41940, Korea.

Tel: +82-53-600-7522, Fax: +82-53-427-3263, E-mail: leejm@knu.ac.kr

Copyright $\odot$ 2019, Oral Biology Research Institute 
tooth loss. Although periodontal bacteria are the causative agents in periodontitis, subsequent progression and disease severity are thought to be determined by the host immune response $[4,5]$.

The host immune response to the microbial challenge results in combination with the microbes in tissue destruction and disease progression. It has been suggested that host immune functions and differences in immune response to periodontal pathogens are important factors in destructive periodontal disease and pro-inflammatory cytokines are released into the blood stream causing many kinds of systemic inflammatory responses, and increase in C-reactive protein (CRP) levels and other markers of inflammation [69].

CRP, an acute phase reactant and a marker of underlying systemic inflammation, has been studied in several kinds of researches [10-13]. These studies show that CRP level $>2.0$ $\mathrm{mg} / \mathrm{L}$ appear to reflect inflammation and an elevated risk for cardiovascular disease [14]. Circulating CRP levels are a marker of systemic inflammation and are associated with periodontal disease, a chronic bacterial infection associated with elevation of pro-inflammatory cytokines and prostaglandin. Elevated immunoglobulin $\mathrm{G}$ induced by bacterial species associated with destructive periodontal diseases is associated with the increase in CRP.

Amar et al. [7] reported that subjects with advanced periodontitis exhibited significantly higher serum levels of high sensitivity CRP (hs-CRP) compared with healthy control subjects. Beckman et al. [15] reported that an increase in CRP levels was associated with a significantly increased risk of a cardiovascular event and Ridker et al. [13] also reported that reducing the CRP can lead to decreases in mortality and morbidity. Microbial components, especially lipopolysaccharide, activate macrophages to synthesize and secrete a variety of pro-inflammatory molecules including a disintegrin and metalloproteinase 17 (ADAM17) protein (tumor necrosis factor- $\alpha$ [TNF- $\alpha]$ converting enzyme) and cathepsin D.

TNF- $\alpha$ is a potent, pro-inflammatory cytokine, secreted primarily by activated monocytes and macrophages, that possesses a broad range of immunomodulating properties. TNF- $\alpha$ plays a pivotal role in the origin and progression of immune mediated disorders such as rheumatoid arthri- tis and Crohn's disease and it is also implicated in diverse neuroimmunological pathologies such as multiple sclerosis, Alzheimers and stroke [16].

The enzyme that processes precursor $\mathrm{TNF}^{-} \alpha$ has previously been identified as a microsomal metalloprotease called TNF- $\alpha$ converting enzyme (TACE). TACE is a member of the ADAM family of proteins which have been implicated in cell interaction events including cell fusion, and has been designated ADAM17 protein $[17,18]$. ADAM17 protein is a membrane-bound disintegrin metalloproteinase that processes the membrane-associated cytokine proTNF- $\alpha$ to a soluble form. Because of its putative involvement in inflammatory diseases, ADAM17 protein represents a significant target for the design of specific synthetic inhibitors as therapeutic agents [19].

A cathepsin is a cysteine protease, a type of protein that breaks apart other proteins, found in many types of cells including those in all animals. There are approximately a dozen members of this family, which are distinguished by their structure and which proteins they cleave. Most of the members become activated at the low $\mathrm{pH}$ found in lysosomes. Thus, the activity of this family lies almost entirely within those organelles.

Cathepsin D, one of cathepsin family, is a soluble lysosomal aspartic endopeptidase synthesized in rough endoplasmic reticulum as preprocathepsin D. Cathepsin D has been studied over last three decades, mainly from the perspective of its role in cancer development and as a suggested independent tumor marker [20].

Numerous physiological functions of cathepsin D have been suggested, based on its ability to cleave structural and functional proteins and peptides. These include metabolic degradation of intracellular proteins, activation and degradation of polypeptide hormones and growth factors, activation of enzymatic precursors, processing of enzyme activators and inhibitors, brain antigen processing and regulation of programmed cell death (apoptosis) [21-23]. Addition to its physiologic function, numerous studies described the importance of procathepsin D/cathepsin D in pathological processes with a majority of studies dealing with its role in, Alzheimer's disease, atherosclerosis, and cancer [24]. While many functions of cathepsin D in the physiological and pathological and pathological processes 
could be attributed to its enzymatic activity, it is suggested that some of its functions in the organism are independent on its protease activity and rely on the ability of procathepsin D/cathepsin D to interact with other important molecules [25-27].

Diabetes mellitus (DM) is one of a number of highly prevalent metabolic disorders, constituting a huge global public health burden. The term "DM" describes a group of disorders characterized by elevated levels of glucose in the blood and abnormalities of carbohydrate, fat and protein metabolism [28]. A number of oral diseases and disorders have been associated with DM, and periodontitis has been identified as a possible risk factor for poor metabolic control in subjects with type 2 diabetes [29].

Recent studies indicate that the co-morbid presence of periodontitis can, in turn, adversely affect diabetic status and the treatment of periodontitis can lead to improved metabolic control in diabetes patients. Current evidence points to a bidirectional interrelationship between diabetes and inflammatory periodontitis [30,31]. Diabetic patients tend to suffer from periodontitis with severe alveolar bone loss caused by lowered immune reaction and delayed tissue recovering. Periodontal pathogens such as $P$. gingivalis lipopolysaccharide (P-LPS) and several cytokines (TNF- $\alpha$, interleukin [IL]-1 and IL-6) stimulate osteoclast differentiation in gingival connective tissue. Then, alveolar bone resorption progresses and the resultant tooth loss falls oral functions. It is confirmed that the incidence of periodontitis is 2- to 3-fold higher in diabetic patients than in nondiabetic subjects. Recently, many researches demonstrated that periodontitis affected diabetic condition, in which periodontal pathogen like P-LPS and TNF- $\alpha$ possibly elevated insulin resistance by inhibiting glucose incorporation into smooth muscle cells [32].

Numerous articles demonstrated an association between metabolic control and periodontal parameters in patients with diabetes or a relationship between periodontal measures and circulating inflammatory markers. However very few cross-sectional studies focused on the association among them at the same time. Also, the particular roles and substrate specificities of ADAM17 protein and cathepsin D have not been described in detail, and the role of ADAM17 protein and cathepsin D in DM is unknown. In inflammato- ry response with bone resorption, the role and interactions of CRP, ADAM17 protein and cathepsin D are not known clearly. And their relative contribution to the pathogenesis of periodontitis and alveolar bone resorption is not entirely established yet. Moreover, none of the in vivo studies simultaneously analyzed each CRP, ADAM17 protein and cathepsin D and their interrelationship for the diabetic and nondiabetic patients with chronic periodontitis.

The purpose of this study was to compare and quantify the expressions of CRP, ADAM17 protein and cathepsin D in gingival tissues of patients with chronic periodontitis accompanied with inflammatory reaction related to alveolar bone resorption with or without type $2 \mathrm{DM}$.

\section{MATERIALS AND METHODS}

\section{Study population and tissue sampling}

The study population was consisted of 12 patients with type $2 \mathrm{DM}$ and chronic periodontitis, 12 patients with chronic periodontitis, and 12 healthy individuals. Marginal gingival tissue samples were obtained in the department of periodontics, Kyungpook national university hospital, South Korea by internal bevel incision at the time of periodontal surgery (including surgical crown lengthening) or tooth extraction and all of the participants signed the Institutional Review Board-approved consent form before the surgery. The study protocol was approved by the Ethical Committee of clinical experiments, Kyungpook National University Hospital (IRB no. KNUH 74005-830).

According to the patient's systemic condition (age, sex, blood glucose level, obesity, and smoking), clinical criteria of gingiva (sulcus bleeding index value and probing depths) and radiographic evidences of bone resorption, each gingival sample was divided into three groups. Group 1 (normal, $\mathrm{n}=12$ ) is clinically healthy gingiva without bleeding, evidence of bone resorption or periodontal pockets, obtained from systemically healthy 12 patients. Group 2 (chronic periodontitis, $n=12$ ) is inflamed gingiva from patients with chronic periodontitis. The diagnosis of chronic periodontitis was established on the basis of clinical and radiographic criteria (bone resorption) according to the classification system for periodontal disease and condition. All patients of 
group 2 were systemically healthy and had more than one periodontal pockets $\geq 5 \mathrm{~mm}$ and at least one pocket with $\geq 5 \mathrm{~mm}$ loss of attachment. All gingival samples were obtained from the teeth with probing depth $\geq 5 \mathrm{~mm}$, swelling of the marginal gingiva, and bleeding corresponding to gingival sulcus bleeding index 3 according to Mühlemann and Son [33]. Group 3 (chronic periodontitis and type 2 $\mathrm{DM}, \mathrm{n}=12$ ) is inflamed gingiva from patients with chronic periodontitis associated with type $2 \mathrm{DM}$. Patients in group 3 were diagnosed type 2 DM before 6 months and showed blood glucose level in postprandial 2 hours of $200 \mathrm{mg} / \mathrm{dL}$ and above. Patients in group 2 and group 3 have similar periodontal condition, but patients in group 2 were systemically healthy and patients in group 3 had type 2 DM. Gingival samples were obtained by similar way described above.

Following surgery, excised tissue specimens were immediately placed on liquid nitrogen and subsequently frozen at $-70^{\circ} \mathrm{C}$.

\section{Protein isolation and Western blotting}

For Western blotting, as previously described technique by Park and Lee [34] and Joo and Lee [35]. Frozen tissues were homogenized in RIPA lysis buffer (10 mM EDTA, $0.15 \mathrm{M} \mathrm{NaCl}$ ) with 1:30 diluted protease inhibitor cocktail (Roche, Mannheim, Germany) [36]. The lysates were sonicated three times for 10 seconds and centrifuged at 12,000 $\mathrm{g}$ for 20 minutes. Protein concentrations of supernatant were routinely determined by a Braford protein assay (Quick Start; BIO-RAD, Hercules, CA, USA) using bovine serum albumin (BSA) as a standard.

Lysates were boiled in sodium dodecyl sulfate (SDS) samples buffer (1 M Tris-HCl [pH 6.8], 40\% glycerol, 8\% SDS, 2\% mercapto-ethanol, $0.002 \%$ Bromophenol blue). Prepared samples were separated by $15 \%$ SDS-polyacrylamide gels and transferred to a polyvinylidene fluoride membrane.

The membranes were subsequently blocked in Tris-buffered saline (TBS) containing 5\% powdered milk and 1\% BSA for 1 hour, and then incubated with polyclonal anti-CRP antibody, anti-ADAM17 protein antibody and anti-cathepsin D antibody (Santa Cruz Biotechnology, Inc., Santa Cruz, CA, USA) for 1.5 hours at room temperature.
The membranes were washed (five times for 5 minutes with Tween 20) and incubated with a horseradish peroxidase-conjugated goat anti-rabbit secondary antibody for anti-CRP antibody, anti-ADAM17 protein antibody and anti-cathepsin D antibody (diluted 1:2,000 in TBS) for 1 hour at room temperature. After additional washing (five times for 5 minutes with Tween 20) the Western blot procedure was completed with an ECL Plus development kit (Amersham, Beckinghamshire, UK).

The relative quantification analysis of CRP, ADAM17 protein, cathepsin D expressions were performed using a densitometer (Image Gauge V 3.46; Koshin Graphic Systems, Fuji Photo Film Co., Tokyo, Japan). After normalization to $\beta$-actin (Abcam, Cambridge, UK) in each sample, levels of CRP, ADAM17 protein and cathepsin D were expressed as a ratio of $\mathrm{CRP}, \mathrm{ADAM} 17$ protein and cathepsin $\mathrm{D} / \beta$-actin and the differences of density between 3 groups were determined.

\section{Statistical analysis of the Western blot results}

All data were presented as means \pm standard deviation and results were statistically analyzed. The CRP, ADAM17 protein and cathepsin D levels were compared using oneway ANOVA followed by Tukey test. $p$-value $<0.05$ was considered to statistically significant.

\section{RESULTS}

Marginal gingival tissue from chronic periodontitis group, chronic periodontitis with type 2 DM group and normal healthy group showed the expression of CRP, ADAM 17 protein and cathepsin D in all samples. To compare CRP expression levels in human gingiva with chronic periodontitis with or without type $2 \mathrm{DM}$, CRP specific antibodies were used to detect the cytokine in the tissues (Fig. 1, 2). Representative Western blot data were presented in Fig. 1. The expression levels of $\beta$-actin were also measured by anti- $\beta$-actin specific Western blot analysis. In order to quantify the level of CRP expression in the groups, the expression levels of CRP in each sample were measured by a densitometer.

The comparison of CRP expression levels was also stud- 


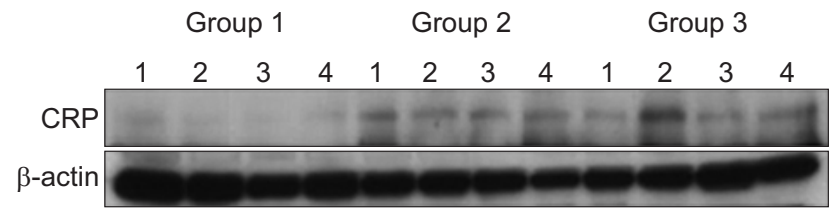

Fig. 1. C-reactive protein (CRP) Western analysis showing 4 representative samples in each group. CRP levels were quantified on the basis of $\beta$-actin levels. CRP corresponding to molecular weight $27 \mathrm{kDa}$ was shown to be expressed in all samples including healthy gingiva, and the expression levels of CRP were increased in order of group 1, group 2 and group 3. Group 1: healthy gingiva from systemically healthy person. Group 2: inflamed gingiva from patient with chronic periodontitis. Group 3: inflamed gingiva from patient with chronic periodontitis and type 2 diabetes mellitus.

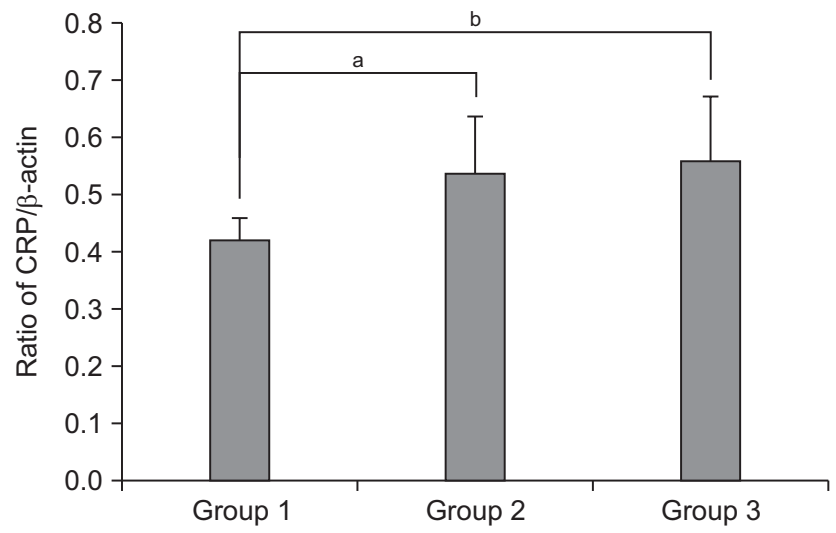

Fig. 2. Graphs showing the average amounts (ratio of C-reactive protein $[\mathrm{CRP}] / \beta$-actin) and standard deviation of CRP level in groups 1 , 2 , and 3 . In the inflamed gingiva with diabetes (group 3), the levels of CRP were significantly increased as compared to group 1 and group 2 $(p<0.05)$. Group 1: healthy gingiva from systemically healthy person. Group 2: inflamed gingiva from patient with chronic periodontitis. Group 3: inflamed gingiva from patient with chronic periodontitis and type $2 \mathrm{DM}$. 'Significant difference between group 1 and group $2(p<0.05)$. ${ }^{b}$ Significant difference between group 1 and group 3 $(p<0.05)$.

ied by detecting about $27 \mathrm{kDa}$ molecular weight of CRP band and measuring their density and areas in all three groups (Fig. 1). The levels of normalized CRP expression are given in Table 1 and summarized as a graph in Fig. 2.

Mean value of CRP expression (ratio of $\mathrm{CRP} / \beta$-actin) was $0.425 \pm 0.035$ for group $1,0.540 \pm 0.099$ for group $2,0.563$ \pm 0.108 for group 3 . There were significant differences between group 1 and group 2, and between group 1 and group 3 but there was no statistically significance $(p<0.05)$ between group 2 and group 3 .

In this study, molecular weight of ADAM17 protein was
Table 1. Normalized CRP expressions by CRP/ $\beta$-actin

\begin{tabular}{lccc}
\hline Sample & Group 1 & Group 2 & Group 3 \\
\hline 1 & 0.476 & 0.589 & 0.563 \\
2 & 0.436 & 0.577 & 0.707 \\
3 & 0.431 & 0.560 & 0.551 \\
4 & 0.444 & 0.628 & 0.617 \\
5 & 0.445 & 0.586 & 0.705 \\
6 & 0.432 & 0.590 & 0.524 \\
7 & 0.463 & 0.570 & 0.720 \\
8 & 0.447 & 0.710 & 0.544 \\
9 & 0.382 & 0.431 & 0.391 \\
10 & 0.373 & 0.428 & 0.410 \\
11 & 0.378 & 0.384 & 0.497 \\
12 & 0.387 & 0.424 & 0.525 \\
Mean \pm SD & $0.425 \pm 0.035$ & $0.540 \pm 0.099$ & $0.563 \pm 0.108$ \\
\hline
\end{tabular}

Group 1, healthy gingiva from systemically healthy person; group 2, inflamed gingiva from patient with chronic periodontitis; group 3 , inflamed gingiva from patient with chronic periodontitis and type 2 diabetes mellitus; CRP, C-reactive protein; SD, standard deviation.

\begin{tabular}{|c|c|c|c|c|c|c|c|c|c|c|c|c|}
\hline & \multicolumn{4}{|c|}{ Group 1} & \multicolumn{4}{|c|}{ Group 2} & \multicolumn{4}{|c|}{ Group 3} \\
\hline & 1 & 2 & 3 & 4 & 1 & 2 & 3 & 4 & 1 & 2 & 3 & 4 \\
\hline $\begin{array}{r}\text { ADAM17 } \\
\text { protein }\end{array}$ & $2=$ & $=$ & - & & 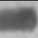 & & a & & $E$ & $=$ & & \\
\hline
\end{tabular}

Fig. 3. A disintegrin and metalloproteinase 17 (ADAM17) protein Western analysis showing 4 representative samples in each group. ADAM17 protein levels were quantified on the basis of $\beta$-actin levels. ADAM17 protein corresponding to molecular weight $85 \mathrm{kDa}$ was shown to be expressed in all samples including healthy gingiva. The expression levels of tumor necrosis factor- $\alpha$ converting enzyme were increased in patients with type 2 diabetes mellitus (DM) than in control healthy subjects. Group 1: healthy gingiva from systemically healthy person. Group 2: inflamed gingiva from patient with chronic periodontitis. Group 3: inflamed gingiva from patient with chronic periodontitis and type $2 \mathrm{DM}$.

identified as $85 \mathrm{kDa}$ size in Western blot analysis (Fig. 3). The normalized quantification data are presented in Table 2 and summarized as a graph in Fig. 4. Mean value of ADAM17 protein expression (ratio of ADAM17 protein/ $\beta$-actin) was $0.761 \pm 0.163$ for group $1,0.942 \pm 0.194$ for group 2 and $0.992 \pm 0.191$ for group 3 . There were significant differences between group 1 and group $3(p<0.05)$ but there were no significant differences $(p<0.05)$ between group 1 and group 2, and between group 2 and group 3 .

The comparison of cathepsin D expression levels was also studied by detecting about $56 \mathrm{kDa}$ molecular weight in Western blot analysis using cathepsin D specific antibody 
Table 2. Normalized ADAM17 protein expressions by ADAM17 protein $/ \beta$-actin

\begin{tabular}{lccc}
\hline sample & Group 1 & Group 2 & Group 3 \\
\hline 1 & 0.919 & 1.095 & 1.282 \\
2 & 0.863 & 1.134 & 1.121 \\
3 & 0.924 & 1.283 & 1.143 \\
4 & 1.076 & 1.091 & 1.271 \\
5 & 0.635 & 0.974 & 1.176 \\
6 & 0.729 & 0.878 & 1.208 \\
7 & 0.717 & 1.084 & 1.084 \\
8 & 0.829 & 1.014 & 1.014 \\
9 & 0.595 & 0.595 & 0.689 \\
10 & 0.635 & 0.749 & 0.671 \\
11 & 0.683 & 0.724 & 1.084 \\
12 & 0.522 & 0.763 & 1.137 \\
Mean \pm SD & $0.761 \pm 0.163$ & $0.942 \pm 0.194$ & $0.992 \pm 0.191$ \\
\hline
\end{tabular}

Group 1, healthy gingiva from systemically healthy person; group 2, inflamed gingiva from patient with chronic periodontitis; group 3, inflamed gingiva from patient with chronic periodontitis and type 2 diabetes mellitus; SD, standard deviation; ADAM17, a disintegrin and metalloproteinase 17 .

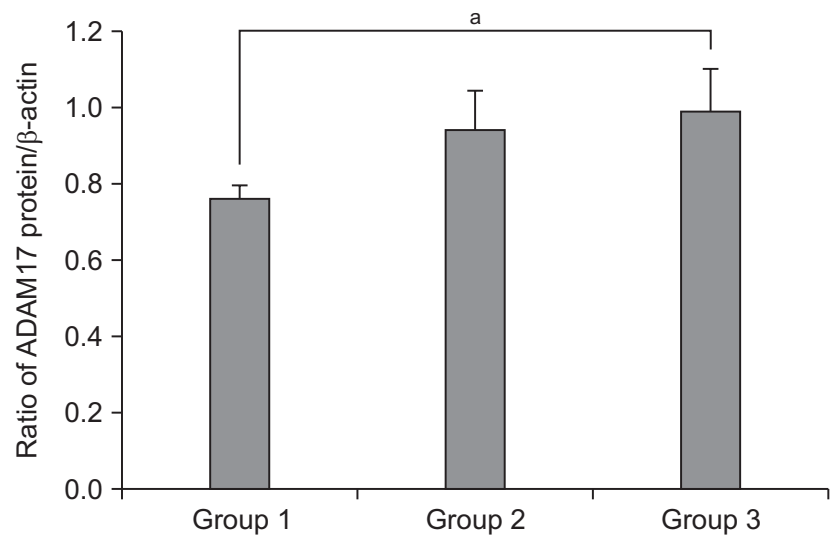

Fig. 4. Graphs showing the average amounts (ratio of a disintegrin and metalloproteinase 17 [ADAM17] protein/ $\beta$-actin) and standard deviation of tumor necrosis factor- $\alpha$ converting enzyme level in group 1,2 and 3. In the inflamed gingiva (with or without diabetes, groups 2 and 3), the levels of ADAM17 protein were higher than those of healthy gingiva $(p<0.05)$. Group 1 : healthy gingiva from systemically healthy person. Group 2: inflamed gingiva from patient with chronic periodontitis. Group 3: inflamed gingiva from patient with chronic periodontitis and type $2 \mathrm{DM}$. ${ }^{\mathrm{a}}$ Significant difference between group 1 and group $3(p<0.05)$.

which detected cathepsin D in all three groups (Fig. 5). The levels of cathepsin D expression were also quantified with $\beta$-actin normalization (Fig. 6) and normalized levels of individual gingival cathepsin D expression are given in Table 3. Mean value of cathepsin D expression (ratio of cathepsin

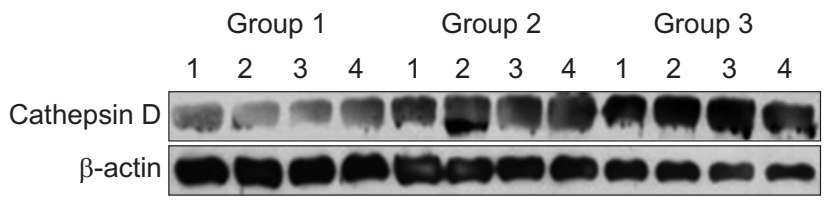

Fig. 5. Cathepsin D Western analysis showing 4 representative samples in each group. Cathepsin D levels were quantified on the basis of $\beta$-actin levels. Cathepsin D corresponding to molecular weight 56 $\mathrm{kDa}$ was shown to be expressed in all samples including healthy gingiva. The expression levels of Cathepsin $\mathrm{D}$ increased in order of group 1 , group 2 and group 3 . Group 1: healthy gingiva from systemically healthy person. Group 2: inflamed gingiva from patient with chronic periodontitis. Group3: inflamed gingiva from patient with chronic periodontitis and type 2 diabetes mellitus.

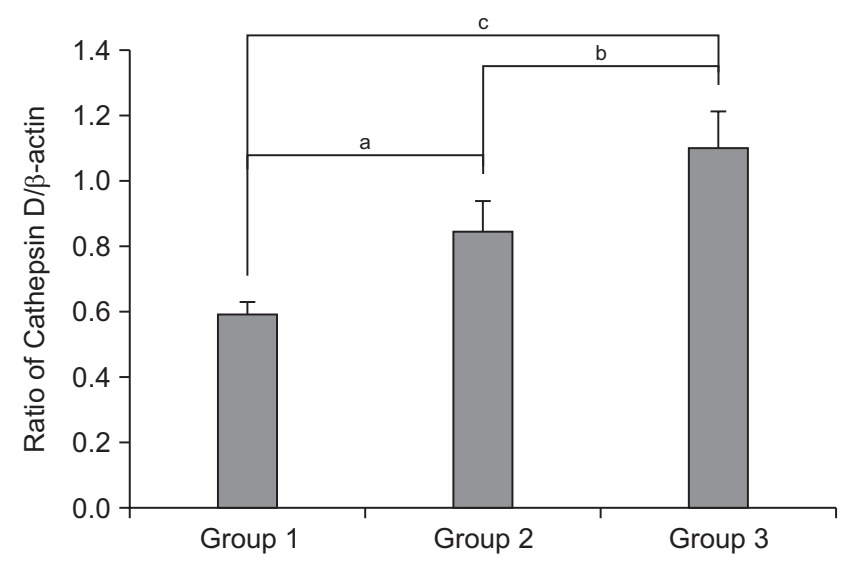

Fig. 6. Graphs showing the average amounts (ratio of Cathepsin D/ $\beta$-actin) and standard deviation of Cathepsin D level in groups 1, 2 and 3. In the inflamed gingiva (with or without diabetes, group 2 and group 3), the levels of Cathepsin D were higher than those of healthy gingiva. Group 1: healthy gingiva from systemically healthy person. Group 2: inflamed gingiva from patient with chronic periodontitis. Group3: inflamed gingiva from patient with chronic periodontitis

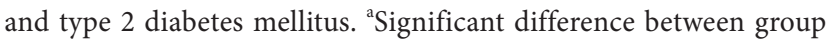
1 and group $2(p<0.05)$. ${ }^{b}$ Significant difference between group 2 and group $3(p<0.05)$. ${ }^{c}$ Significant difference between group 1 and group 3 $(p<0.05)$.

$\mathrm{D} / \beta$-actin) was $0.591 \pm 0.169$ for group $1,0.839 \pm 0.099$ for group 2 and $1.099 \pm 0.163$ for group 3 . There were significant differences between group 1 and group $2(p<0.05)$, between group 1 and group $3(p<0.05)$, and between group 2 and group $3(p<0.05)$.

\section{DISCUSSION}

DM describes a group of disorders characterized by elevated levels of glucose in the blood and abnormalities of 
Table 3. Normalized cathepsin D expressions by cathepsin $\mathrm{D} / \beta$-actin

\begin{tabular}{lccc}
\hline sample & Group 1 & Group 2 & Group 3 \\
\hline 1 & 0.566 & 0.931 & 1.170 \\
2 & 0.466 & 0.876 & 1.203 \\
3 & 0.551 & 0.817 & 1.367 \\
4 & 0.644 & 0.913 & 1.049 \\
5 & 0.326 & 0.979 & 1.133 \\
6 & 0.434 & 0.962 & 1.155 \\
7 & 0.698 & 0.802 & 1.159 \\
8 & 0.883 & 0.834 & 1.073 \\
9 & 0.832 & 0.704 & 0.759 \\
10 & 0.441 & 0.623 & 0.867 \\
11 & 0.526 & 0.791 & 0.974 \\
12 & 0.725 & 0.831 & 1.282 \\
Mean \pm SD & $0.591 \pm 0.169$ & $0.839 \pm 0.099$ & $1.099 \pm 0.163$ \\
\hline
\end{tabular}

Group 1, healthy gingiva from systemically healthy person; group 2, inflamed gingiva from patient with chronic periodontitis; group 3, inflamed gingiva from patient with chronic periodontitis and type 2 diabetes mellitus; SD, standard deviation.

carbohydrate, fat and protein metabolism. A number of oral diseases and disorders have been associated with DM, and periodontitis has been identified as a possible risk factor for poor metabolic control in subjects with diabetes.

DM is an important risk factor for periodontitis. DM also determines changes in bacterial population and production of inflammatory mediators, and reduces the efficacy of the host response. Well controlled diabetes does not cause a major risk of periodontitis and improve the results of the periodontal initial therapy and of the eventual surgical therapy [37].

At present, there is strong evidence to suggest that the incidence and severity of periodontitis is influenced by the presence or absence of DM as well as by the degree of diabetes control by patients. Elevated blood glucose levels in poorly controlled diabetics result in an increase of protein glycosylation leading to amplified formation of so-called Advanced Glycation End products (AGEs). AGEs are glucose products that have the ability to attract and stimulate inflammatory cells to produce inflammatory cytokines, elevating the risk of periodontal attachment and alveolar bone loss. Gram-negative periodontal infection significantly decreases glucose tolerance and can lead, like other types of inflammation, to an increase in the severity of diabetes. Thus, diabetes and periodontal disease form a system in which periodontitis is aggravated and metabolic control of blood glucose levels becomes more difficult [38].

Several mechanisms are involved in the physiopathology of periodontal disease associated with DM: production of advanced glycosylation products, deficient immune response, inheritance of certain genetic polymorphisms, alterations in blood vessels, conjunctive tissue and salivary composition [39].

The purpose of this study was to quantify and compare the expression of CRP, ADAM17 protein and cathepsin D in the gingival tissues of the patients with chronic periodontitis associated to type $2 \mathrm{DM}$, in order to understand the contribution of these proteins to periodontal destruction accompanied with alveolar bone resorption in type 2 diabetic patients.

The CRP is an acute-phase protein, synthesized mainly in the liver and regulated primarily by a circulating interleukin-6 level. There has been much concern about the relationship between the CRP and other chronic diseases, such as DM and periodontitis [40]. The CRP level was shown to elevated in patients with type $2 \mathrm{DM}$ in a large national survey and to be a powerful risk determinant for the prediction of incident diabetes. A persistently raised CRP level was associated with advanced periodontal disease [41-43]. Also, it has been suggested that periodontitis is associated with elevated CRP in both serum and gingival crevicular fluid (GCF) and periodontal infections contribute to an elevated circulating CRP level.

Periodontitis is a result of the host response to an anaerobic bacterial insult. This inflammatory response can be measured as an increase in hs-CRP levels and levels of proinflammatory cytokines, both locally and systemically. The systemic effects of periodontal disease have been considered either as a risk factor or a co-morbidity for disease as different as rheumatoid arthritis, ischemic cardiovascular disease and premature labor, all possibly due to increases in the inflammatory host response [44].

In this study, the quantitative analysis of CRP level showed that CRP expression was rather increased in inflamed gingiva with or without type 2 DM compared to healthy gingiva. The differences among three groups were statistically significant between group 1 and group 2 and between group 1 and group $3(p<0.05)$ (Table 1, Fig. 2). $\mathrm{CRP}$ level in group 3 is higher than group 2, but there was 
no statistical significance. But it assumed that there was slightly higher inflammatory response in chronic periodontitis associated to type $2 \mathrm{DM}$.

Our result of this research tends to support recent research by Wu and Chen [45] who reported that the serum CRP levels in type 2 diabetes patients with periodontitis and periodontitis and type 2 diabetes were significantly higher than those in healthy group. Serum CRP levels in type 2 diabetes patients with periodontitis were the highest and were significantly higher than that in periodontitis group and type 2 diabetes group. Therefore, it can be assumed that both serum and GCF CRP levels may be involved in the progression of periodontal inflammation associated to type $2 \mathrm{DM}$. But the CRP levels in serum didn't always correlate to the CRP levels in GCF.

The positive correlation between the severity of periodontitis and glycemic metabolic level also concurred with a series of previous findings [9,46]. It is possible that periodontal infection contributes to an elevated serum CRP level that subsequently aggravates the glycemic metabolic control in diabetes. Hsueh and Bruemmer [47]. demonstrated that the ongoing acute phase response is induced by cytokines, and is reflected in elevated circulating inflammatory markers including CRP, IL-1, IL-6, TNF- $\alpha$.

It seems that level of CRP was increased by influence of Diabetes during progression of inflammation. TNF- $\alpha$ is one of the most common pro-inflammatory cytokines responsible for various inflammatory disorders. It plays an important role in the origin and progression of many kinds of autoimmune disease conditions [48].

TNF- $\alpha$ is produced in the body as pro-TNF, the inactive form of the cytokine as 233 a membrane anchored precursor. It is transformed into the active and soluble form by limited proteolysis at the Ala 76 and Val 77 bond. The proteinase responsible for this cleavage is called ADAM17 protein, also known as TACE. Thus, ADAM17 protein is the major sheddase of TNF- $\alpha$ and is essential for the generation of soluble, mature TNF- $\alpha$.

ADAM17 protein has been reported to be an indispensable regulator of almost every cellular event from proliferation to migration. The central role of ADAM17 protein in cell regulation is rooted in its diverse array of substrates: cytokines, growth factors, and their receptors as well as adhesion molecules are activated or inactivated by their cleavage with ADAM17 protein [49]. Inhibition of generation of active form of TNF- $\alpha$ is a promising therapy for various inflammatory disorders. Therefore, the inhibition of ADAM17 protein, which is responsible for processing inactive form of TNF- $\alpha$ into its active soluble form, is an encouraging target.

In this study, the quantitative analysis of ADAM17 protein level showed that ADAM17 protein expression was rather increased in inflamed gingiva with or without type $2 \mathrm{DM}$ compared to healthy gingiva. The differences among three groups were statistically significant between group 1 and group $3(p<0.05)$ (Table 3, Fig. 6). Even though there were not statistically significant between group1 and group 2, between group 2 and group 3, it can be assumed that there was slightly higher inflammatory response in chronic periodontitis associated to type $2 \mathrm{DM}$. These results are similar to previous researches in which of Bostanci et al. [50] and Monroy et al. [51].

Bostanci et al. [50] reported that total ADAM17 protein amounts in GCF were higher in persons with chronic and aggressive periodontitis than in those with gingivitis or in healthy persons, and ADAM17 protein concentrations in GCF were higher in persons with chronic and aggressive periodontitis than in those with gingivitis, although not significantly higher than in healthy persons. Monroy A. et al. reported that ADAM17 protein expression, and ADAM17 protein, TNF- $\alpha$ levels were increased in type 2 diabetes, and positively correlated with insulin resistance [51]. Even though there were numerous articles about ADAM17 protein on systemic disease treatment, there was few data and report concerning ADAM17 protein on periodontal disease with or without type 2 diabetes.

The aspartic proteinase cathepsin D is a member of the large family of cysteine proteases. Unlike other proteases, which are mostly secretory proteins, procathepsin D is sorted to the lysosomes. Cathepsin D is involved in antigen processing in concerted action with the cysteine proteases cathepsin B and L [20-23]. Cathepsin D is an important regulator of apoptotic pathways in cells. It acts at different stage of intrinsic and extrinsic pathway of apoptosis. Cathepsin D can either induce apoptosis in presence of cytotoxic factors, but in certain studies an inhibitory role in 
apoptosis was also reported [20].

In this study, the quantitative analysis of cathepsin D level showed that cathepsin D expression was rather increased in inflamed gingiva with or without type 2 DM compared to healthy gingiva. The differences among three groups were statistically significant between group 1 and group 2 and between group 1 and group 3, and between group 2 and group $3(p<0.05)$ (Table 2 , Fig. 4). These results are similar to previous researches in which of Jotterand and Cimasoni [52] and Feron et al. [53]. Jotterand and Cimasoni [52] reported that there was a positive and statistically significant correlation between the cathepsin D specific activity and the degree of gingiva inflammation, and Feron et al. [53] has demonstrated that there was an increase of cathepsin D activity found in serum of diabetic patients compared to control subjects. A significant correlation between cathepsin D activity and the degree of gingival inflammation was found supporting the hypothesis of participation in the destruction of periodontal tissues during periodontal disease. It assumed that there was higher inflammatory response in chronic periodontitis associated to type 2 DM. The design and synthesis of specific cathepsin D inhibitors are also of great interest and may have important research and therapeutical consequences in the future.

Thus, it can be assumed that CRP Level is an indicative of systemic inflammation from either a periodontal infection or inflammatory disease and ADAM17 protein, one of the inflammatory mediators, may be closely associated with the cathepsin D expression which is indispensable for various inflammatory disorders.

In conclusion, this study demonstrated that the expression levels of CRP, ADAM17 protein, and cathepsin D had increasing tendency in human gingival inflamed tissue from chronic periodontitis with type 2 DM showed increased level compared to healthy gingiva from non-periodontitis patient or periodontitis patient without type 2 DM. It can be assumed that CRP, ADAM17 protein and cathepsin D may be partly involved in the progression of periodontal inflammation associated to type $2 \mathrm{DM}$. The present results support the concept that CRP, ADAM17 protein and cathepsin D play important roles in tissue destruction and could be used as indicator materials on diagnosis and treat- ment modality of inflammatory disease including chronic periodontitis. Finally, it is suggested that more studies are needed to investigate the effect and interrelationship between CRP, ADAM17 protein and cathepsin D other inflammatory mediators that affect the progression of periodontal disease with or without DM at a higher level.

\section{CONFLICTS OF INTEREST}

The authors declare that they have no competing interests.

\section{ORCID}

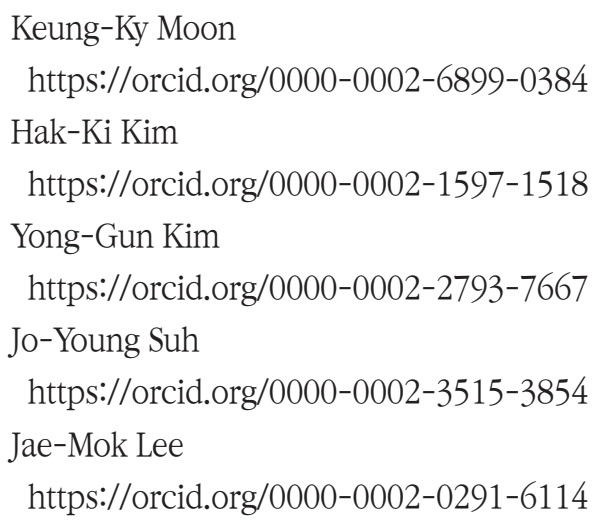

\section{REFERENCES}

1. Gholizadeh P, Pormohammad A, Eslami H, Shokouhi B, Fakhrzadeh V, Kafil HS. Oral pathogenesis of Aggregatibacter actinomycetemcomitans. Microb Pathog 2017;113:303-311. doi: 10.1016/j.micpath.2017.11.001.

2. Socransky SS, Haffajee AD. Periodontal microbial ecology. Periodontol 2000 2005;38:135-187. doi: 10.1111/j.16000757.2005.00107.x.

3. Torrungruang K, Jitpakdeebordin S, Charatkulangkun O, Gleebbua Y. Porphyromonas gingivalis, Aggregatibacter actinomycetemcomitans, and Treponema denticola / Prevotella intermedia co-infection are associated with severe periodontitis in a Thai population. PLoS One 2015;10:e0136646. doi: 10.1371/journal.pone.0136646.

4. Beck JD, Moss KL, Morelli T, Offenbacher S. Periodontal profile class is associated with prevalent diabetes, coronary heart disease, stroke, and systemic markers of C-reactive protein and interleukin-6. J Periodontol 2018;89:157-165. doi: 10.1002/JPER.17-0426.

5. Kampits C, Montenegro MM, Ribeiro IW, Furtado MV, Polanczyk CA, Rösing CK, Haas AN. Periodontal disease and 
inflammatory blood cytokines in patients with stable coronary artery disease. J Appl Oral Sci 2016;24:352-358. doi: 10.1590/1678-775720160082.

6. Noack B, Genco RJ, Trevisan M, Grossi S, Zambon JJ, De Nardin E. Periodontal infections contribute to elevated systemic c-reactive protein level. J Periodontol 2001;72:1221-1227. doi: 10.1902/jop.2000.72.9.1221.

7. Amar S, Gokce N, Morgan S, Loukideli M, Van Dyke TE, Vita JA. Periodontal disease is associated with brachial artery endothelial dysfunction and systemic inflammation. Arterioscler Thromb Vasc Biol 2003;23:1245-1249. doi: 10.1161/01.ATV.0000078603.90302.4A.

8. Buhlin K, Gustafsson A, Pockley AG, Frostegård J, Klinge B. Risk factors for cardiovascular disease in patients with periodontitis. Eur Heart J 2003;24:2099-2107. doi: 10.1016/j.ehj.2003.09.016.

9. Craig RG, Yip JK, So MK, Boylan RJ, Socransky SS, Haffajee $\mathrm{AD}$. Relationship of destructive periodontal disease to the acute-phase response. J Periodontol 2003;74:1007-1016. doi: 10.1902/jop.2003.74.7.1007.

10. Pietilä K, Harmoinen A, Hermens W, Simoons ML, Van de Werf F, Verstraete M. Serum C-reactive protein and infarct size in myocardial infarct patients with a closed versus an open infarct-related coronary artery after thrombolytic therapy. Eur Heart J 1993;14:915-919. doi: 10.1093/eurheartj/14.7.915.

11. Ridker PM, Cushman M, Stampfer MJ, Tracy RP, Hennekens $\mathrm{CH}$. Inflammation, aspirin, and the risk of cardiovascular disease in apparently healthy men. N Engl J Med 1997;336:973-979. doi: 10.1056/NEJM199704033361401.

12. Ridker PM. On evolutionary biology, inflammation, infection, and the causes of atherosclerosis. Circulation 2002;105:2-4. doi: 10.1161/circ.105.1.2.

13. Ridker PM, Rifai N, Rose L, Buring JE, Cook NR. Comparison of C-reactive protein and low-density lipoprotein cholesterol levels in the prediction of first cardiovascular events. N Engl J Med 2002;347:1557-1565. doi: 10.1056/ NEJMoa021993.

14. Ridker PM, Morrow DA. C-reactive protein, inflammation, and coronary risk. Cardiol Clin 2003;21:315-325. doi: 10.1016/S0733-8651(03)00079-1.

15. Beckman JA, Preis O, Ridker PM, Gerhard-Herman M. Comparison of usefulness of inflammatory markers in patients with versus without peripheral arterial disease in predicting adverse cardiovascular outcomes (myocardial infarction, stroke, and death). Am J Cardiol 2005;96:13741378. doi: 10.1016/j.amjcard.2005.07.041.

16. Amour A, Slocombe PM, Webster A, Butler M, Knight CG, Smith BJ, Stephens PE, Shelley C, Hutton M, Knäuper V, Docherty AJ, Murphy G. TNF-alpha converting enzyme (TACE) is inhibited by TIMP-3. FEBS Lett 1998;435:39-44. doi: 10.1016/s0014-5793(98)01031-x.

17. Huovila AP, Almeida EA, White JM. ADAMs and cell fusion.
Curr Opin Cell Biol 1996;8:692-699. doi: 10.1016/s09550674(96)80111-6.

18. Blobel CP. Metalloprotease-disintegrins: links to cell adhesion and cleavage of TNF alpha and Notch. Cell 1997;90:589-592. doi: 10.1016/s0092-8674(00)80519-x.

19. Moss ML, Jin SL, Becherer JD, Bickett DM, Burkhart W, Chen WJ, Hassler D, Leesnitzer MT, McGeehan G, Milla M, Moyer M, Rocque W, Seaton T, Schoenen F, Warner J, Willard D. Structural features and biochemical properties of TNF-alpha converting enzyme (TACE). J Neuroimmunol 1997;72:127-129. doi: 10.1016/s0165-5728(96)00180-4.

20. Benes P, Vetvicka V, Fusek M. Cathepsin D--many functions of one aspartic protease. Crit Rev Oncol Hematol 2008;68:12-28. doi: 10.1016/j.critrevonc.2008.02.008.

21. Baechle D, Flad T, Cansier A, Steffen H, Schittek B, Tolson J, Herrmann T, Dihazi H, Beck A, Mueller GA, Mueller M, Stevanovic S, Garbe C, Mueller CA, Kalbacher H. Cathepsin D is present in human eccrine sweat and involved in the postsecretory processing of the antimicrobial peptide DCD-1L. J Biol Chem 2006;281:5406-5415. doi: 10.1074/ jbc.M504670200.

22. Hakala JK, Oksjoki R, Laine P, Du H, Grabowski GA, Kovanen PT, Pentikäinen MO. Lysosomal enzymes are released from cultured human macrophages, hydrolyze LDL in vitro, and are present extracellularly in human atherosclerotic lesions. Arterioscler Thromb Vasc Biol 2003;23:1430-1436. doi: 10.1161/01. ATV.0000077207.49221.06.

23. Morikawa W, Yamamoto K, Ishikawa S, Takemoto S, Ono M, Fukushi Ji, Naito S, Nozaki C, Iwanaga S, Kuwano M. Angiostatin generation by cathepsin D secreted by human prostate carcinoma cells. J Biol Chem 2000;275:3891238920. doi: 10.1074/jbc.M005402200.

24. Minarowska A, Minarowski L, Karwowska A, Gacko M. Regulatory role of cathepsin D in apoptosis. Folia Histochem Cytobiol 2007;45:159-163.

25. Laurent-Matha V, Maruani-Herrmann S, Prébois C, Beaujouin M, Glondu M, Noël A, Alvarez-Gonzalez ML, Blacher S, Coopman P, Baghdiguian S, Gilles C, Loncarek J, Freiss G, Vignon F, Liaudet-Coopman E. Catalytically inactive human cathepsin D triggers fibroblast invasive growth. J Cell Biol 2005;168:489-499. doi: 10.1083/jcb.200403078.

26. Vashishta A, Saraswat Ohri S, Vetvickova J, Fusek M, U1richova J, Vetvicka V. Procathepsin D secreted by HaCaT keratinocyte cells - a novel regulator of keratinocyte growth. Eur J Cell Biol 2007;86:303-313. doi: 10.1016/ j.ejcb.2007.03.008.

27. Schestkowa O, Geisel D, Jacob R, Hasilik A. The catalytically inactive precursor of cathepsin $\mathrm{D}$ induces apoptosis in human fibroblasts and HeLa cells. J Cell Biochem 2007;101:1558-1566. doi: 10.1002/jcb.21269.

28. Lamster IB, Lalla E, Borgnakke WS, Taylor GW. The relationship between oral health and diabetes mellitus. J Am 
Dent Assoc 2008;139 Suppl:19S-24S. doi: 10.14219/jada. archive.2008.0363.

29. Graves DT, Liu R, Alikhani M, Al-Mashat H, Trackman PC. Diabetes-enhanced inflammation and apoptosis--impact on periodontal pathology. J Dent Res 2006;85:15-21. doi: 10.1177/154405910608500103.

30. Grossi SG, Genco RJ. Periodontal disease and diabetes mellitus: a two-way relationship. Ann Periodontol 1998;3:5161. doi: 10.1902/annals.1998.3.1.51.

31. Research, Science and Therapy Committee of The American Academy of Periodontology. Position paper: diabetes and periodontal diseases. J Periodontol 2000;71:664-678. doi: 10.1902/jop.2000.71.4.664.

32. Nagata T. Relationhip between diabetes and periodontal disease. Clin Calcium 2009;19:1291-1298. doi: CliCa090912911298.

33. Mühlemann HR, Son S. Gingival sulcus bleeding--a leading symptom in initial gingivitis. Helv Odontol Acta 1971;15:107-113.

34. Park JW, Lee JM. The comparison of IL-6, elastase and $\alpha$-PI expressions in human chronic periodontitis with type 2 diabetes mellitus. J Korean Acad Periodontol 2007;37(Suppl):325-338. doi: 10.5051/jkape.2007.37.Suppl.325.

35. Joo SD, Lee JM. The comparison of inflammatory mediator expression in gingival tissues from human chronic periodontitis patients with and without type 2 diabetes mellitus. J Korean Acad Periodontol 2007;37(Suppl):353-369. doi: 10.5051/jkape.2007.37.Suppl.353.

36. Cho JY, Xing S, Liu X, Buckwalter TL, Hwa L, Sferra TJ, Chiu IM, Jhiang SM. Expression and activity of human $\mathrm{Na} / / \mathrm{I}-$ symporter in human glioma cells by adenovirusmediated gene delivery. Gene Ther 2000;7:740-749. doi: 10.1038/sj.gt.3301170.

37. Garofalo GS. Relationships between diabetes mellitus and periodontal disease: current knowledges and therapeutic prospects. Clin Ter 2008;159:97-104.

38. Kasaj A, Gortan-Kasaj A, Willerhausen B, Hoffmann O, Angelov N, Zafiropoulos GG. The relationship of periodontitis and diabetes mellitus. Acta Med Croatica 2007;61:369-374.

39. Alves C, Andion J, Brandão M, Menezes R. Pathogenic aspects of the periodontal disease associated to diabetes mellitus. Arq Bras Endocrinol Metabol 2007;51:1050-1057.

40. Chen L, Wei B, Li J, Liu F, Xuan D, Xie B, Zhang J. Association of periodontal parameters with metabolic level and systemic inflammatory markers in patients with type 2 diabetes. J Periodontol 2010;81:364-371. doi: 10.1902/ jop.2009.090544.

41. King DE, Mainous AG 3rd, Buchanan TA, Pearson WS. Creactive protein and glycemic control in adults with diabetes. Diabetes Care 2003;26:1535-1539. doi: 10.2337/ diacare.26.5.1535.

42. Pradhan AD, Manson JE, Rifai N, Buring JE, Ridker PM. Creactive protein, interleukin 6 , and risk of developing type 2 diabetes mellitus. JAMA 2001;286:327-334. doi: 10.1001/ jama.286.3.327.

43. Linden GJ, McClean K, Young I, Evans A, Kee F. Persistently raised $\mathrm{C}$-reactive protein levels are associated with advanced periodontal disease. J Clin Periodontol 2008;35:741-747. doi: 10.1111/j.1600-051X.2008.01288.x.

44. Renvert S, Lindahl C, Roos-Jansåker AM, Lessem J. Shortterm effects of an anti-inflammatory treatment on clinical parameters and serum levels of $\mathrm{C}$-reactive protein and proinflammatory cytokines in subjects with periodontitis. J Periodontol 2009;80:892-900. doi: 10.1902/ jop.2009.080552.

45. Wu CL, Chen FL. [Evaluation of C-reactive protein levels in serum and gingival crevicular fluid in type 2 diabetes patients with periodontitis]. Shanghai Kou Qiang Yi Xue 2009;18:132-135. Chinese.

46. Slade GD, Offenbacher S, Beck JD, Heiss G, Pankow JS. Acute-phase inflammatory response to periodontal disease in the US population. J Dent Res 2000;79:49-57. doi: 10.1177/00220345000790010701.

47. Hsueh WA, Bruemmer D. Peroxisome proliferator-activated receptor gamma: implications for cardiovascular disease. Hypertension 2004;43:297-305. doi: 10.1161/01. HYP.0000113626.76571.5b.

48. Bahia MS, Silakari O. Tumor necrosis factor alpha converting enzyme: an encouraging target for various inflammatory disorders. Chem Biol Drug Des 2010;75:415-443. doi: 10.1111/j.1747-0285.2010.00950.x.

49. DasGupta S, Murumkar PR, Giridhar R, Yadav MR. Current perspective of TACE inhibitors: a review. Bioorg Med Chem 2009;17:444-459. doi: 10.1016/j.bmc.2008.11.067.

50. Bostanci N, Emingil G, Afacan B, Han B, Ilgenli T, Atilla G, Hughes FJ, Belibasakis GN. Tumor necrosis factor-alpha-converting enzyme (TACE) levels in periodontal diseases. J Dent Res 2008;87:273-277. doi: 10.1177/154405910808700311.

51. Monroy A, Kamath S, Chavez AO, Centonze VE, Veerasamy M, Barrentine A, Wewer JJ, Coletta DK, Jenkinson C, Jhingan RM, Smokler D, Reyna S, Musi N, Khokka R, Federici M, Tripathy D, DeFronzo RA, Folli F. Impaired regulation of the TNF-alpha converting enzyme/tissue inhibitor of metalloproteinase 3 proteolytic system in skeletal muscle of obese type 2 diabetic patients: a new mechanism of insulin resistance in humans. Diabetologia 2009;52:2169-2181. doi: 10.1007/s00125-009-1451-3.

52. Jotterand H, Cimasoni G. [Cathepsin D in the connective tissue and epithelium of inflammed human gingival. J Biol Buccale 1977;5:333-342. French.

53. Feron D, Begu-Le Corroller A, Piot JM, Frelicot C, Vialettes B, Fruitier-Arnaudin I. Significant lower VVH7-like immunoreactivity serum level in diabetic patients: evidence for independence from metabolic control and three key enzymes in hemorphin metabolism, cathepsin D, ACE and DPP-IV. Peptides 2009;30:256-261. doi: 10.1016/ j.peptides.2008.11.004. 